\title{
Luchar por participar: la protesta feminista en la Iglesia Católica durante el franquismo ${ }^{1}$
}

\section{Fighting for joining in: The Feminist Protest within the Catholic Church in Franco's Spain}

\author{
Celia Valiente \\ Universidad Carlos III de Madrid \\ celia.valiente@uc3m.es
}

Recibido: 7-III-2016

Aceptado: 4-VII-2016

\section{Resumen}

En un contexto político de ausencia de ciudadanía en el que las autoridades franquistas negaron el reconocimiento de numerosos derechos individuales, ciertas mujeres, en asociaciones de la Iglesia o próximas a ella, lucharon por que mejorara el estatus de la población femenina. Trataron de que las mujeres ampliaran su grado de participación en la Iglesia y la sociedad, y no tanto que la élite política les confiriera derechos civiles, políticos y sociales.

Palabras clave: Género, Feminismo, Iglesia Católica, España, Franco, Siglo XX.

\begin{abstract}
In Franco's Spain, political authorities refused to acknowledge numberless individual rights. In this political context, some women actively involved in the Catholic Church organizations (or other movements close to the Church) did their best to improve women's status. The main aim of these activists was to increase women's role in society and within the Church, rather than to persuade political authorities to acknowledge their civil, political and social rights
\end{abstract}

Keywords: Gender, Feminism, Catholic Church, Spain, Franco, 20th Century.

1. Este artículo se deriva del proyecto de investigación HA2012-32539 del Plan Nacional de I+D+i. Está dedicado a la memoria de Juan J. Linz, mi director de tesis y referente intelectual. 


\section{Introducción}

La ciudadanía suele entenderse, según concepciones clásicas, por ejemplo, la formulada por T. H. Marshall, como un conjunto de derechos civiles, políticos y sociales. En este artículo argumento que otra lectura de este autor permite concebir la ciudadanía de manera diferente, como un estatus que posibilita a las personas participar en una comunidad en calidad de miembros plenos, las cuales albergan un sentimiento de pertenencia a dicha colectividad. Con ayuda de esta segunda definición de la ciudadanía, basada, más que en los derechos individuales, en la participación en la comunidad y en la identidad colectiva, considero que durante el franquismo ciertas mujeres dentro de la Iglesia Católica ("Iglesia" en lo que sigue) reivindicaron este estatus al demandar, principal pero no exclusivamente, el acceso a la educación, en general, y a la formación religiosa, en particular, así como un papel más activo en la Iglesia y la sociedad, y no tanto la obtención de derechos individuales (civiles, políticos y sociales). Desde esta perspectiva analizo la protesta feminista dentro de la Iglesia, en concreto, dos grupos que proporcionaron dirigentes y activistas a dicha movilización: el Seminario de Estudios Sociológicos sobre la Mujer y el liderazgo nacional de Mujeres de Acción Católica.

Este artículo está organizado en tres secciones. La primera comprende el marco analítico, mientras que en la segunda presento el caso de estudio, justifico su elección y describo las fuentes. En la tercera examino la mencionada protesta en sus esfuerzos por que las mujeres ampliaran sus ámbitos de participación en la Iglesia y la sociedad. Este escrito no es una breve historia de los dos grupos citados, sino una investigación de sus demandas por conseguir el estatus de miembros plenos de la congregación de los fieles y de la sociedad.

\section{Marco analítico}

Las investigaciones en humanidades y ciencias sociales utilizan múltiples definiciones del concepto de ciudadanía. Suelen concebirla como un conjunto de derechos conferidos por el Estado. Por ejemplo, según la ya clásica propuesta en 1950 por T. H. Marshall en el ensayo "Ciudadanía y clase social", constituye un compendio de derechos civiles, políticos y sociales. Los derechos civiles son, en sus propias palabras, "los necesarios para la libertad individual" y engloban los de "la libertad de la persona, la libertad de expresión, pensamiento y religión, el derecho de poseer propiedades y firmar contratos, así como el derecho a la justicia". De otro lado, los derechos políticos de un individuo consisten en "la participación en el ejercicio del poder político como miembro de un cuerpo investido de autoridad política o como elector de los miem- 
bros de dicho cuerpo". Por último, los derechos sociales engloban desde "el derecho a un grado mínimo de bienestar económico y seguridad, hasta los de compartir plenamente la herencia cultural de la sociedad y vivir una existencia de ser civilizado de acuerdo con los estándares imperantes en la sociedad". ${ }^{2}$

Analizando su sociedad de procedencia, Inglaterra, Marshall propuso que el período formativo de los derechos civiles fue principalmente el siglo XVIII, el de los políticos sobre todo el XIX, y el de los sociales fundamentalmente el $\mathrm{XX} .{ }^{3}$ Las instituciones más directamente asociadas a los derechos civiles eran los tribunales de justicia, a los derechos políticos el Parlamento y los ayuntamientos, y a los sociales el sistema educativo y los servicios sociales. ${ }^{4}$

Según la concepción de ciudadanía de Marshall expuesta en los párrafos anteriores cabría concluir, como ya han hecho otros autores, que el Estado franquista negó la condición ciudadana a los españoles, pues el régimen no reconoció ni sus derechos políticos ni muchos civiles. Las principales disposiciones legislativas, de hecho, evitaron los vocablos "ciudadanos" o "ciudadanía". ${ }^{5}$ Las mujeres, además, especialmente las casadas (pero no los hombres), se vieron privadas de ciertos derechos, tales como el de suscribir ciertos contratos. Por ejemplo, hasta mayo de 1975 les fue requerida la autorización de sus maridos para firmar contratos de trabajo y ejercer el comercio. ${ }^{6}$ Centrando nuestra atención en las mujeres, dicha conceptualización de la ciudadanía nos llevaría a analizar los esfuerzos individuales y colectivos de algunas de ellas por que el Estado reconociera sus derechos civiles y políticos (o al menos algunos de ellos).

No obstante lo anterior, en este artículo argumento que la mencionada obra de Marshall contiene dos dimensiones útiles para investigar los intentos de ciertas mujeres, a título individual y colectivo, por mejorar la situación del conjunto de las mujeres. Estos intentos no consistieron principalmente en reivindicar que el Estado otorgara derechos individuales (civiles y políticos) a la población femenina (aunque pudieran en algún momento demandarlos). Como explico a continuación, me refiero a la visión de Marshall (i) de los ciu-

2. MARSHALL, Thomas H., Citizenship and social class and other essays, Cambridge, Cambridge University Press, 1950, pp. 10-11. En este artículo, la traducción del inglés al castellano ha sido realizada por la autora.

3. Ibid, p. 14.

4. Ibid, p. 11.

5. CAPRARELLA, Marcello, "La ciudadanía secuestrada: La etapa franquista", en PÉREZ LEDESMA, Manuel (ed.): De súbditos a ciudadanos: Una historia de la ciudadanía en España, Madrid, Centro de Estudios Políticos y Constitucionales, 2007, p. 311.

6. RUIZ, Rosario, ¿Eternas menores? Las mujeres en el franquismo, Madrid, Biblioteca Nueva, 2007; MORCILLO GÓMEZ, Aurora, En cuerpo y alma: Ser mujer en tiempos de Franco, Madrid, Siglo XXI, 2015. 
dadanos como miembros plenos de una comunidad y (ii) del sentimiento de pertenencia a la misma. Es cierto que estos dos aspectos de la obra de Marshall son secundarios respecto a los expuestos arriba, pero ello no impide que podamos utilizarlos para analizar otros fenómenos sociales distintos de los que empíricamente captaron la atención del autor (Inglaterra) y de los que constituyeron su preocupación intelectual central en el citado ensayo. ${ }^{\top}$

(i) En primer lugar, para Marshall, la ciudadanía permite a quienes tienen derechos vivir como miembros integrados en una colectividad. En su propia prosa: "La ciudadanía es un estatus otorgado a aquellos que son miembros plenos de la comunidad." "La "comunidad" a la que se refiere Marshall es una de carácter político, esto es, un país, gobernado por un Estado que confiere progresivamente derechos a quienes viven bajo su autoridad. ${ }^{9}$ Pero nada en la obra de este autor prohíbe que consideremos la "comunidad" de otras maneras, por ejemplo, como una sociedad, sin poner entonces el foco de atención en el Estado, o como un conjunto de creyentes, y entonces quienes establecen las normas que deben respetar sus miembros son las autoridades religiosas, las cuales no tienen necesariamente que coincidir con las estatales. Desde esta dimensión de la ciudadanía podemos analizar los esfuerzos de ciertas mujeres durante la dictadura de Franco por que el conjunto de las mujeres tomara parte en un número creciente de ámbitos, requiriera o no este mayor grado de participación la concesión de derechos por parte del Estado.

(ii) En segundo lugar, en la obra de Marshall, pertenecer a la comunidad implica experimentar que se es miembro de un grupo distinto de la familia y más amplio. Imaginando una comunidad política, Marshall habla del sentimiento nacional o patriótico. ${ }^{10}$ Pero si, como he defendido antes, imaginamos otro tipo de colectividad, por ejemplo, una sociedad o un conjunto de creyentes, cabe deducir que la pertenencia a la misma comprende no sólo derechos y deberes sino un sentimiento de formar parte de una comunidad o, según el vocabulario de los estudios sobre los movimientos sociales, una "identidad colectiva". De otro lado, es cierto que el largo proceso histórico de la construcción de la ciudadanía es en la obra de Marshall un fenómeno que tiene lugar principalmente desde arriba hacia abajo, en el que el Estado va otorgando progresivamente derechos a los individuos. Pero el propio Marshall indica que

\footnotetext{
7. Como él mismo afirmó, el principal interés de Marshall en este escrito residía en analizar el impacto de la ciudadanía en la desigualdad social (MARSHALL, Thomas H., Citizenship and social class..., pp. 28, 85).

8. Ibid, p. 28.

9. Ibid, p. 12.

10. Ibid, pp. 40-41.
} 
ciertas personas luchan por que se les reconozcan los derechos. También afirma que la conciencia colectiva de raigambre en la comunidad aparece y/o se consolida no sólo cuando los ciudadanos ejercen sus derechos, sino cuando luchan por que se les confieran. ${ }^{11}$

En síntesis, según los argumentos centrales en la obra de Marshall, la ciudadanía comprende sobre todo un conjunto de derechos concedidos por el Estado a los miembros de un país (o a parte de ellos) en el transcurso de décadas o siglos; ciertos deberes van asociados a estos derechos. Esta parte de la obra de Marshall nos llevaría a examinar los (pocos) derechos conferidos por el Estado franquista a los gobernados, y a analizar los esfuerzos individuales y colectivos de ciertas mujeres por que las autoridades políticas reconocieran sus derechos civiles y políticos (o por suplantarlas por otras que los reconocieran). Por contraste, dos aspectos (secundarios) de la obra de Marshall nos sugieren que (i) el estatus de ciudadano permite, a quienes lo disfrutan, participar como miembros plenos en la comunidad, y la clave entonces reside en esta participación. Además, las colectividades importantes para las personas no son sólo las políticas (los países) sino también otras, por ejemplo, la propia sociedad o, en el caso de las personas religiosas, la comunidad de creyentes. (ii) De otro lado, ser ciudadano implica albergar un sentimiento de raigambre en un grupo más amplio que el familiar, y este sentimiento surge cuando se disfruta del ejercicio de los derechos pero también cuando se lucha por la consecución de la ciudadanía. Estas dos dimensiones de la obra de Marshall nos animarían a indagar si durante el franquismo algunas mujeres, con independencia de los poquísimos derechos reconocidos por las autoridades políticas, intentaron que las mujeres pudieran participar (y participaran) como miembros plenos de una comunidad, entendiendo que ésta no consistía solo en el país sino también en la propia sociedad o la misma Iglesia, y animadas, en esta lucha, por la convicción de pertenecer a estas otras colectividades. El resto del artículo trata de dilucidar la cuestión con ayuda de un caso empírico, el cual presento a continuación, así como las fuentes utilizadas para su análisis.

\section{Mujeres católicas en el franquismo: un estudio de caso y fuentes}

Los estudios académicos suelen mostrar, explícita o implícitamente, que la segunda oleada de la movilización feminista en España surgió, en sus atisbos a finales de los sesenta, pero sobre todo en los setenta, en el ámbito clandestino de la oposición a la dictadura de Franco, compuesto, entre otros, por partidos de izquierda y sindicatos. El grueso de este movimiento feminista con frecuen-

11. Ibid, pp. 40-42. 
cia es descrito como laico, cuando no directamente como anti-religioso. ${ }^{12}$ Esta caracterización resulta parcialmente comprensible ya que la religión, en los más variados contextos históricos y geográficos, se ha utilizado para mantener a las mujeres en una posición subordinada respecto a los hombres en las propias comunidades de creyentes y en la sociedad en su conjunto. Por ejemplo, para conseguirlo, la Iglesia ha difundido sin descanso diversos extractos de la Biblia acerca de la inferioridad innata de las mujeres, o del deber de obediencia a los maridos por parte de las esposas. La Iglesia es una institución profundamente desigualitaria. La llave para alcanzar cualquier puesto de toma de decisiones es el sacerdocio, el cual sólo puede ser ejercido por varones. ${ }^{13}$ Por lo que se refiere a España, la Iglesia ha sido descrita tradicionalmente por la historiografía como una institución que ha contribuido de modo significativo a la opresión de las mujeres, al predicar su confinamiento en los hogares o los conventos, la restricción de su sexualidad a la procreación dentro del matrimonio canónico, e incluso su inferioridad moral por comparación con los hombres. ${ }^{14}$

No obstante lo anterior, Pamela Radcliff ha sostenido, convincentemente, que a la historiografía sobre España le resulta difícil reconocer que ciertas mujeres encontraron su propia voz y autonomía en contextos distintos del antifranquismo. Pero dada la feroz represión del régimen sobre la oposición clandestina, este medio fue, forzosamente, minoritario. Como demuestra la propia investigación de Radcliff, en ámbitos permitidos (o tolerados) por la dictadura pudieron participar muchas más mujeres que en la clandestinidad de la oposición, y en algunos de ellos plantearon reivindicaciones de género en contra de lo dictado por las autoridades políticas, por ejemplo, en las asociaciones de amas de casa patrocinadas por el partido único y, en menor medi$\mathrm{da}$, en las asociaciones de vecinos. ${ }^{15}$ Defiendo que la Iglesia fue uno de estos ámbitos donde ciertas mujeres pudieron realizar (y realizaron) esfuerzos por que mejorara el estatus de las mujeres como grupo. ${ }^{16}$

12. DI FEBO, Giuliana, Resistencia y movimiento de mujeres en España (1936-1976), Barcelona, Icaria, 1976; ESCARIO, Pilar, Inés ALBERDI y Ana I. LÓPEZ-ACCOTTO, Lo personal es político: El movimiento feminista en la transición, Madrid, Instituto de la Mujer, 1996; SCANLON, Geraldine M., La polémica feminista en la España contemporánea (1868-1974), Madrid, Siglo XXI, 1976.

13. KATZENSTEIN, Mary F, Faithful and fearless: Moving feminist protest inside the Church and military, Princeton, Princeton University Press, 1998, pp. 12-13.

14. M. SCANLON, Geraldine M., La polémica feminista..., pp. 159-160, 211-225, 354-356.

15. RADCLIFF, Pamela, Making democratic citizens in Spain: Civil society and the popular origins of the transition, 1960-78, Palgrave, Macmillan, 2011.

16. VALIENTE, Celia, "Social movements in abeyance in non-democracies: The women's movement in Franco's Spain", Research in Social Movements, Conflicts and Change, 38 (2015), pp. 259-90. 
Una clarificación terminológica es necesaria aquí. Los "movimientos de mujeres" comprenden todas las "actividades de organización de las mujeres, explícitamente como mujeres, para promover o detener el cambio social". Son "movimientos feministas" aquellos que "cuestionan e intentan cambiar las relaciones que subordinan a las mujeres respecto de los hombres", si bien pueden tratar también de modificar otras relaciones sociales. ${ }^{17}$ Por tanto, los movimientos feministas son un tipo de movimientos de mujeres. Repárese en que estas definiciones implican que los movimientos de mujeres pueden encontrarse en la izquierda y en la derecha del espectro político, y que no imponen que los movimientos feministas luchen exclusivamente por la igualdad de género. Ciertos investigadores utilizan la palabra "feminista" únicamente cuando lo hacen las propias activistas a quienes estudian para referirse a sí mismas. ${ }^{18}$ Algunas de las mujeres a las que investigo utilizaban el adjetivo "feminista" al caracterizarse a ellas mismas mientras que otras no lo hacían. ${ }^{19}$ No obstante, denomino "feministas" o "feministas (católicas)" a todas ellas porque todas combatieron al menos algún aspecto de la desigualdad de género; en esta decisión sigo al reputado estudio sobre la protesta feminista en la Iglesia Católica y el ejército en Estados Unidos. ${ }^{20}$ Utilizo indistintamente las expresiones "movimiento feminista" y "protesta feminista" para evitar repeticiones. Entiendo, con Mary Nash, que históricamente en distintos países han surgido diferentes versiones de feminismo, ${ }^{21}$ y enfatizo que, dentro de un mismo país, también han aparecido múltiples (y con frecuencia contrapuestas) variedades de movimien-

17. FERREE, Myra M. y Carol M. MUELLER, "Feminism and the women's movement: A global perspective", David A. SNOW, David A., Sarah A. SOULE y Hanspeter KRIESI (eds.), The Blackwell Companion to Social Movements, Mablen (MA), Blackwell, 2004, p. 577.

18. Por ejemplo, RAY, R. y A. C. KORTEWEG: "Women's movements in the Third World: Identity, mobilization, and autonomy", Annual Review of Sociology, 25 (1999), pp. 47-71.

19. ÁLVAREZ, Lilí, El seglarismo y su integridad, Madrid, Taurus, 1959, p. 13; BELLOSILLO, Pilar, "Los movimientos de liberación de la mujer" Incunable, 9, 310 (1975), pp. 8-9; CAMPO ALANGE, María, Mi atardecer entre dos mundos: Recuerdos y cavilaciones, Barcelona, Planeta, 1983, p. 226; MORENO, Mónica, "De la caridad al compromiso: Las mujeres de Acción Católica (1958-1968)", Historia Contemporánea, 26 (2003), pp. 239-265. 2003, p. 249.

20. KATZENSTEIN, Mary F, Faithful and fearless, pp. 20-21, 86-97. El feminismo católico ha sido estudiado en un período anterior al examinado aquí, entre otros lugares, en: BLASCO HERRANZ, Inmaculada, Paradojas de la ortodoxia: Política de masas y militancia católica femenina en España (1919-1939), Zaragoza, Prensas Universitarias de Zaragoza, 2003; LLONA GONZÁLEZ, Miren, "El feminismo católico en los años veinte y sus antecedentes ideológicos", Vasconia, n²5 (1998), pp. 283-99.

21. NASH, Mary, "Experiencia y aprendizaje: La formación histórica de los feminismos en España", Historia Social, 20 (1994), pp. 151-172; OFFEN, Karen, "Defining feminism: A comparative historical approach", Signs, vol.14, nº (1988), pp. 119-57 
tos feministas dado que, en todas las sociedades, las mujeres forman un grupo internamente heterogéneo.

En este artículo analizo dos grupos formados mayoritariamente por mujeres de clase alta o media-alta: el Seminario Sociológico de Estudios sobre la Mujer (SESM o "Seminario" en lo que sigue) y el liderazgo nacional de Mujeres de Acción Católica. Son dos tipos de organizaciones muy distintas. El SESM fue un grupo pequeño (nueve mujeres) radicado en Madrid dedicado a la reflexión y al estudio de la situación de las mujeres. Fue fundado en 1960 por María Laffitte, por matrimonio condesa de Campo Alange, más conocida como María Campo Alange. Con ayuda de su amiga Lilí Álvarez, ${ }^{22}$ reclutó al resto del grupo entre mujeres con carrera universitaria y que trabajaran fuera de casa. Permaneció activo hasta 1986, año en que falleció su fundadora. Por contraste, Mujeres de Acción Católica fue una de las organizaciones femeninas de masas de implantación nacional de la Iglesia. ${ }^{23}$

La bibliografía sobre el tema y las obras publicadas de ciertas activistas y líderes constituyen fuentes principales de este estudio. Además, consulté todos los números entre 1955 y 1966 de Circular para Dirigentes, una publicación mensual de Mujeres de Acción Católica para sus líderes, y todos los números entre 1952 y 1966 de Senda, una publicación de la organización dirigida a un público femenino más amplio.

Son también fuentes centrales para mi análisis quince entrevistas; permítaseme presentarlas con cierto detalle. En cuanto al SESM, en 2009-2010 entrevisté a las cuatro activistas vivas cuyas condiciones físicas y mentales les permitían participar en esta técnica de investigación: Concepción Borreguero, María Jiménez, Carmen Pérez-Seoane y Purificación Salas. Respecto a los miembros del SESM que ya habían fallecido o vivían pero no podían ser entrevistadas, entrevisté a familiares directos suyos. ${ }^{24}$

Acerca del liderazgo nacional de Acción Católica de la Mujer, los trabajos académicos sobre la organización sostienen que en el franquismo la batalla

22. Lilí Álvarez, autora de obras sobre religión, deporte y la condición de las mujeres, fue más conocida por haber cosechado importantes éxitos nacionales e internacionales en varios deportes, entre otros, haber logrado tres veces clasificarse como finalista en el campeonato de tenis de Wimbledon en los años veinte.

23. Por ejemplo, en 1953 contaba con 172.056 miembros, BLASCO, Inmaculada, "Las mujeres de Acción Católica durante el primer franquismo", en IV ENCUENTRO DE INVESTIGADORES DEL FRANQUISMO (ed.), Tiempos de silencio: Actas del IV Encuentro de Investigadores del Franquismo, Valencia, 17-19 noviembre de 1999, Alzira, 7 i Mig, 1999, p. 160. En 1966-67 había 65 comisiones diocesanas de la organización en las 66 diócesis existentes, MORENO, Mónica, "De la caridad...", p. 245.

24. Entrevistas a: C. Álvarez de Miranda; P. Álvarez de Miranda; del Amor; Rodríguez-Ponga; Salamanca; Vindel. 
por la "promoción de la mujer" comenzó a finales de los años cincuenta. Sugieren que la orientación feminista de parte de sus líderes duró hasta finales de los sesenta, cuando los dirigentes de la mayor parte de las ramas de Acción Católica (no sólo las pertenecientes a la de mujeres adultas) dimitieron después de intensos conflictos con la jerarquía. ${ }^{25}$ Tuvo lugar dicha movilización, entonces, durante las presidencias de Pilar Bellosillo (1952-1963) y Carmen Victory (1963-1968). Elaboré una base de datos con todos los miembros de los Consejos Superiores (en los sesenta llamados Consejos Nacionales) de la organización en las dos presidencias mencionadas, a fin de encontrar a dirigentes nacionales que pudieran ser entrevistadas. En 2009-2010 entrevisté a la Presidenta de la organización entre 1963 y 1968 (Carmen Victory) y a tres líderes nacionales (Ángela R. de Silva, María Quereizaeta y Carmen Salas). Afirmo con confianza que estas cuatro entrevistadas componen la totalidad de dirigentes nacionales que en 2009-2010 vivían y podían ser entrevistadas, podían ser encontradas por un investigador tras esfuerzos exhaustivos, y accedieron a hablar conmigo (otras dos líderes declinaron la invitación). También entrevisté al Consiliario Nacional de la organización entre 1963 y 1966 (Antonio Aradillas).

Las entrevistas fueron semi-estructuradas y duraron entre 60 y 90 minutos. La mayoría de los entrevistados, salvo los familiares de miembros del SESM, tenía ochenta o más años. Grabé todas las entrevistas y las transcribí yo misma. Si bien todas resultaron útiles para la investigación, por constreñimientos de espacio en este artículo sólo cito textualmente las realizadas a activistas católicas.

\section{La protesta feminista en la Iglesia durante el franquismo}

En esta sección describo, en primer lugar, las reivindicaciones de la movilización feminista en la Iglesia dirigidas a ampliar los campos de actuación de las mujeres en la sociedad y la Iglesia. Para conseguir dicho objetivo, les animaron a que accedieran a la educación, en general, y a la formación religiosa, en particular, les propusieron que se implicaran en actividades más allá del hogar o del convento, por ejemplo, en el voluntariado, y sostuvieron que el matrimonio y la maternidad (o los votos religiosos) no constituían las únicas opciones posibles para las adultas, a la vez que defendían la soltería. En segundo lugar, muestro que las feministas católicas plantearon estas demandas sintiéndose

25. MORENO, Mónica, "De la caridad..."; SALAS, María y María T. RODRÍGUEZ, Pilar Bellosillo: Nueva imagen de la mujer en la Iglesia, Madrid, Federación de Movimientos de la Acción Católica Española, 2004, pp. 40-61. 
parte de la Iglesia, entendida ésta como pueblo de Dios donde el laicado debía desempeñar un papel central. Por último, aclaro que, en ocasiones, reivindicaron a las autoridades políticas el reconocimiento de derechos individuales para las españolas, si bien esta batalla no constituyó su lucha principal. Las demandas planteadas por las feministas católicas iban, desde luego, más allá del ideal femenino propugnado por las autoridades franquistas y la propia jerarquía eclesiástica, ${ }^{26} \mathrm{y}$ generaron oposición entre los prelados, la élite política y la población en general. Como sintetizó en la entrevista Concepción Borreguero, miembro del SESM, al referirse a los hombres: "pensábamos que los hombres no nos valoraban (...); sí, eran muy finos, eran muy agradables, pero en el fondo [pensaban que lo que hacíamos en el Seminario] era una tontería de las mujeres españolas". ${ }^{27}$

\section{Incrementar la participación de las mujeres en la sociedad y la Iglesia}

(i) Observando la sociedad y la Iglesia de su época, las feministas católicas identificaron el déficit educativo y de formación religiosa de la abrumadora mayoría de las mujeres como una barrera para su participación en ambos ámbitos. Por lo que se refiere al SESM, el acceso de las mujeres a la educación constituyó una de las principales batallas que libró este grupo (si no la principal). Ya antes de la fundación del Seminario, María Campo Alange había llamado la atención sobre la cuestión. En el libro titulado La secreta guerra de los sexos sostuvo que el estado de ignorancia en que vivía la mayoría de las mujeres no reflejaba su inferioridad mental innata, sino el hecho de que no se les hubiese permitido desarrollar sus capacidades. Desde antiguo, los dos sexos habían establecido una lucha soterrada sin cuartel por la posesión de la cultura. Al vencer los hombres, a lo largo de la historia habían dominado al otro sexo privando a la humanidad de las aportaciones que las mujeres hubieran podido realizar. ${ }^{28}$ Una vez constituido el SESM, en muchos escritos criticó sin descanso el Seminario la escasa educación formal recibida por la abrumadora mayoría de las españolas. ${ }^{29}$ Algunos de los miembros del grupo pade-

26. MORCILLO, Aurora G., True Catholic womanhood: Gender ideology in Franco's Spain, Dekalb, Northern Illinois University Press, 2000.

27. Concepción BORREGUERO: Entrevista.

28. CAMPO ALANGE, María, La secreta guerra de los sexos, Madrid, Revista de Occidente, 1948.

29. ÁLVAREZ, Lilí et al.: Mujer y aceleración histórica, Madrid, Cuadernos para el Diálogo, 1970; CAMPO ALANGE, María (ed.), Habla la mujer: Resultado de un sondeo sobre la juventud actual, Madrid, Cuadernos para el Diálogo, 1967; DE LA GÁNDARA, Consuelo, "Promoción cultural", Cuadernos para el Diálogo número extraordinario sobre la mujer ([1965] 1970), p. 12. 
cieron en carne propia esta desventaja de género. La fundadora del SESM, María Campo Alange, pese a su elevado origen social, no recibió en su niñez y adolescencia formación reglada; abiertamente lamentó en sus memorias que ni su familia ni su confesor desearan que se instruyera ni que leyera, con la excepción de las vidas de los santos, que ella encontraba muy aburridas ${ }^{30}$ y esta queja fue confirmada en la entrevista a un miembro del Seminario. ${ }^{31}$

Repárese en que esta reivindicación del acceso de las mujeres a la educación no iba dirigida principalmente al Estado. En aquella época las españolas, en teoría, tenían abierto el acceso a ciertas instituciones educativas, si bien la oferta formativa efectiva distaba muchísimo de garantizar la igualdad en este sentido de niños y jóvenes de ambos sexos. ${ }^{32}$ Esta demanda iba sobre todo dirigida a las propias mujeres, para que aprovecharan las oportunidades formativas existentes y, en el caso de que tuvieran hijas, hicieran por que éstas las aprovecharan. Como afirmó la fundadora del SESM, la misión del Seminario consistió en "despertar las conciencias especialmente somnolientas de las mujeres españolas. La empresa estaba en su principio erizada de espinos." ${ }^{33}$ Esta reivindicación iba también dirigida a toda la sociedad, a fin de que no aceptara como un hecho natural, inevitable y deseable que la mitad de la población se hallara sumida en la ignorancia. ${ }^{34}$ Por su profesión, algunas mujeres del SESM se encontraban en una posición idónea para observar atentamente, de modo directo, la realidad educativa española: Elena Catena y Consuelo de la Gándara impartían clases en la universidad, mientras que Purificación Salas lo hacía en la enseñanza secundaria. El Seminario reivindicó el avance educativo femenino no sólo a fin de que las mujeres adquirieran formación para el empleo o, como se había defendido anteriormente en ocasiones, para que educasen bien a sus hijos y apoyasen y comprendiesen a sus esposos, ${ }^{35}$ sino para "dotar a la mujer de una capacidad intelectual, de un sentido de la responsabilidad y de una formación moral que le permitan insertarse en la sociedad española actual." ${ }^{36}$

Las feministas católicas insistieron asimismo en que las españolas ampliaran sus escasos conocimientos en materia religiosa. El SESM también diagnosticó este problema de la ignorancia femenina en temas religiosos, pese a que

30. CAMPO ALANGE, María: Mi atardecer..., pp. 11-12, 14.

31. María JIMÉNEZ: Entrevista.

32. ÁLVAREZ, Lilí et al., Mujer y aceleración..., pp. 17, 21.

33. CAMPO ALANGE, María, Mi atardecer..., p. 122.

34. ÁLVAREZ, Lilí et al., Mujer y aceleración..., pp. 42-44.

35. Ibid., p. 58.

36. DE LA GÁNDARA, Consuelo, "Promoción cultural", p. 12. 
muchas mujeres eran asiduas practicantes católicas. Observó que numerosas de ellas vivían superficialmente la religión, basándose en la tradición y las prácticas rutinarias, teniendo escasos conocimientos de la fe que profesaban y no estando al tanto de las transformaciones experimentadas por la Iglesia en el Concilio Vaticano II. ${ }^{37}$ Los propios miembros del Seminario habían padecido tal ignorancia religiosa. María Campo Alange, en sus memorias, describe su religiosidad de infancia y juventud como una basada en el desconocimiento de la Biblia, por haber estado su lectura prohibida durante mucho tiempo y, en cierta medida, en la superstición: en la creencia en el poder de las reliquias y en la intervención de los santos para resolver asuntos triviales de aquellos que les recitaban oraciones y ofrecían sacrificios. ${ }^{38}$

Mujeres de Acción Católica, además de denunciar la escasa formación religiosa de la mayor parte de las españolas, puso en pie programas formativos dentro de la propia organización para paliar el problema. Es más, como explico a continuación, fue en su énfasis en un tipo específico de instrucción religiosa donde se manifestó el viraje feminista de parte de su liderazgo nacional. La organización fue fundada en España en 1919 para extender el catolicismo en una sociedad en proceso de transformación debido a una incipiente industrialización y modernización. Si bien sus principales actuaciones fueron religiosas y caritativas, durante la Segunda República (1931-1936) también emprendió actividades políticas, por ejemplo, recabando el voto femenino a favor de partidos conservadores. Esta combinación de iniciativas religiosas y políticas continuó durante la Guerra Civil (1936-1939) con el apoyo al bando nacional en la retaguardia, y se mantuvo durante los primeros años del régimen franquista. Mujeres de Acción Católica se empleó entonces con ahínco en la re-cristianización del país (tras la presunta descristianización del mismo en años precedentes), desplegando iniciativas como el apostolado en lugares varios incluidas las cárceles de mujeres, el impulso a ceremonias religiosas como el rosario y la peregrinación a santuarios, la propagación del matrimonio canónico entre las parejas que convivían sin haberlo contraído y del bautismo entre los niños de familias republicanas que no lo habían recibido, el combate incesante contra la inmodestia y a favor del recato en el vestir femenino, y la lucha contra la inmoralidad en las costumbres en lugares públicos como teatros, salas de baile y playas. ${ }^{39}$

Dado el pasado conservador y pío de esta organización, sorprende que a finales de los años cincuenta y principios de los sesenta empezara a conver-

37. CAMPO ALANGE, María (ed.), Habla la mujer...

38. CAMPO ALANGE, María, Mi atardecer..., pp. 17-18, 38-39.

39. MORENO, Mónica, "De la caridad...", pp. 241-243. 
tirse en una plataforma para el activismo feminista católico (de sus líderes), pero así sucedió. Las dirigentes de Mujeres de Acción Católica, de modo incansable, plantearon para las mujeres la necesidad de contar con una formación religiosa, la cual habrían, además, de mejorar y profundizar continuamente. Ya en los años cincuenta la Presidenta Nacional, Pilar Bellosillo, y su equipo modificaron los programas de formación ofrecida (e impuesta) a otras líderes, cuadros y bases de la organización, los cuales incluyeron una pedagogía activa (que daba la palabra y la iniciativa a las mujeres). En los cursillos tradicionales un sacerdote disertaba sobre aspectos doctrinales y morales, mientras las cursillistas escuchaban. En los nuevos, impartidos ya no sólo por un eclesiástico, sino por éste y una dirigente de Mujeres de Acción Católica, se instaba a las asistentes a observar la realidad, pensar críticamente sobre ella (desde una perspectiva católica) y obrar para mejorarla en consonancia con los mandatos de esta religión (según la triple máxima de "ver, juzgar y actuar"). Continuamente se exhortaba a las mujeres a que fueran católicas activas en vez de comportarse como almas pasivas y sumisas. Estos programas formativos pretendían que las participantes adoptaran por sí mismas compromisos tras la reflexión, en lugar de obedecer mandatos procedentes de otros, por ejemplo, de los ordenados. ${ }^{40}$

La insistencia del liderazgo de Mujeres de Acción Católica en la formación religiosa continua de los miembros de la organización encontró no pocas resistencias en el interior de la misma. Los mencionados programas formativos fueron contestados por numerosas militantes, quienes en materia religiosa preferían ser tuteladas por los sacerdotes, en vez de tratar de pensar y tomar decisiones por su cuenta, según indicaba la máxima de "ver, juzgar y actuar". ${ }^{41}$

(ii) Por lo que se refiere al ideal de vida de una mujer joven y adulta, las feministas católicas, una y otra vez, manifestaron que el matrimonio y la maternidad no constituían las actividades a las que las mujeres debían dedicar la totalidad de las energías. Lilí Álvarez, miembro del SESM, entendía que la mayoría de las mujeres se encargasen de la gestión de su hogar y de cuidar de sus familiares, y valoraba positivamente que lo hicieran porque, en su opinión, desarrollaban sus inclinaciones y dotes naturales y proporcionaban bienestar a sus allegados, pero entendía que quienes reducían su existencia a ser amas de casa no permitían "el consciente despertar al plano de las culturales y humanas empresas de la civilización, en las cuales se desarrolla la personalidad", "se

40. Antonio ARADILLAS: Entrevista; María QUEREIZAETA: Entrevista; SALAS, María, Las siete palabras de Mary Salas, Madrid, Promoción Popular Católica, 1996; Carmen VICTORY: Entrevista.

41. MORENO, Mónica, "De la caridad...”, pp. 257-258. 
contentaban [con] poco" y "se engañaban a sí mismas". Concluyó que "la mujer no puede dejar de ser lo que ha sido siempre: el hada tutelar, la cálida "constructora del nido', pero no se la puede reducir a eso tampoco". ${ }^{42}$ Existía un vasto campo de actuación en la sociedad y la Iglesia que las activistas católicas reclamaron para sí: el voluntariado. Según recordaba María Salas, miembro del SESM y dirigente de Mujeres de Acción Católica, en esta organización se exhortaba a cada militante como sigue: "No preguntes lo que la Iglesia, la sociedad, puede hacer por ti, sino lo que tú puedes hacer por ellas. En este caso, además, de forma totalmente gratuita." 43

La demanda de participación femenina en la sociedad, por ejemplo, en actividades de voluntariado, esto es, más allá del ámbito familiar, sintonizaba con ciertos cambios en la doctrina pontificia sobre las mujeres. Por ejemplo, ya en los años cuarenta Pío XII declaró que, si bien históricamente las católicas habían servido a Dios confinadas en sus casas o en los conventos, en los tiempos actuales debían difundir la palabra de Dios más allá del hogar y del claustro. Las menciones a Pío XII y a estas declaraciones (y a otras en este sentido) aparecen con frecuencia en las publicaciones feministas católicas y en alguna de las entrevistas realizadas para esta investigación, y formaron parte de los materiales utilizados en los cursos de formación de Mujeres de Acción Católica. ${ }^{44}$ Pese a esta y otras recomendaciones pontificias, en su esfuerzo por ampliar el campo de actuación de las mujeres en la Iglesia en España, las dirigentes de Mujeres de Acción Católica se enfrentaron continuamente a la oposición de numerosos prelados. Incluso en los años sesenta, la mayor parte de la jerarquía española propugnaba que las mujeres ejercitaran su piedad en la reclusión de su casa, el convento o, como mucho, la parroquia, desempeñando allí las tareas más humildes de ayuda en la sacristía o arrodilladas con fervor en los bancos de la iglesia. ${ }^{45}$

Dada su elevada extracción social, las feministas católicas que ahora estudio disponían de un recurso clave para el voluntariado, el tiempo, al poder delegar los quehaceres domésticos y de cuidados en personal remunerado que trabajaba en sus hogares, en un país, España, caracterizado por una larga tradición

42. ÁLVAREZ, Lilí, "La valoración del ama de casa, clave para el destino femenino", Cuadernos para el Diálogo, número extraordinario sobre la mujer ([1965] 1970), pp. 28-30.

43. SALAS, María, Las siete palabras..., p. 22.

44. PÍO XII, "La mujer en el momento actual", Circular para Dirigentes, 133 (1956), pp. 14-16; Carmen SALAS: Entrevista; SALAS, María, Las siete palabras..., pp. 51-52; SALAS, María y María T. RODRÍGUEZ, Pilar Bellosillo..., 42-43; SENDA, "Pío XII y la mujer", Senda, 153 (1956), pp. 6-7.

45. Carmen VICTORY: Entrevista. 
histórica de servicio doméstico. Por contraste, las de posición social modesta no contaban con esta facilidad. De modo incipiente en los años cincuenta, pero sobre todo en los sesenta, Mujeres de Acción Católica llevó a cabo diversas iniciativas dirigidas a la gestión eficiente del trabajo doméstico y de cuidados, que prometían el ahorro de tiempo en la realización de estas tareas bajo el lema "Menos tiempo para las cosas, más para las personas". Por ejemplo, insertó sesiones sobre la cuestión en cursos dirigidos a mujeres rurales, ${ }^{46}$ proporcionó cursos monográficos sobre el tema a las urbanas ${ }^{47}$ y desde sus publicaciones, tales como Senda, animó a sus lectoras a progresar en esta dirección. La racionalización y simplificación de los quehaceres domésticos y de cuidados fue alabada también por el SESM. ${ }^{48}$

Es fácil con ojos actuales criticar el elitismo de este tipo de iniciativas, por el que las mujeres de clase alta recomendaban a las de clases modestas eficiencia en la gestión del hogar sin entender los serios obstáculos estructurales a los que habían de hacer frente estas últimas, entre otros, los bajos ingresos familiares, las deficientes (cuando no pésimas) condiciones de muchas viviendas o la falta de infraestructuras básicas en barrios desfavorecidos. Pero también cabe realizar otra interpretación más positiva: las feministas católicas entendían que todas las mujeres, con independencia de su clase social, habían de ampliar su campo de participación en la Iglesia y la sociedad, en vez de proponer que sólo lo hicieran las que gozaban de una posición económica desahogada. Posiblemente pensando en las facilidades que para el voluntariado proporcionaba el privilegio económico, María Salas reflexionaba, ya en la tercera edad, como sigue acerca de su dilatada trayectoria activista:

"A lo largo de mi vida he dedicado muchas horas al trabajo voluntario en favor de los demás. No sólo en la propia A.C. [Acción Católica], sino en obras derivadas de ella y posteriormente en actividades de educación de adultos y cultura popular. Es una gran satisfacción poder ayudar a los demás desinteresadamente, y también un lujo, porque no todos pueden hacerlo". ${ }^{49}$

(iii) En realidad, las feministas católicas no consideraron que el matrimonio y la maternidad (aun complementados con el voluntariado) o la vida religiosa constituyeran los únicos roles que las mujeres adultas debieran desempe-

46. MUJERES DE ACCIÓN CATÓlICA, Para ti, mujer, Madrid, Mujeres de Acción Católica, 1957; SENDA, "La Acción Católica: Centros de formación familiar", Senda, 229, agosto (1962), p. 15.

47. MARTíN, María J., y María L. BOUVARD, "Cursillo de racionalización del trabajo doméstico: Hablan las organizadoras y las alumnas”, Senda, 250, junio (1964), pp. 4-6.

48. Por ejemplo, ÁLVAREZ, Lilí, "La valoración...", p. 29.

49. SALAS, María, Las siete palabras..., p. 23. 
ñar en la comunidad, según mandaba el imperativo tradicional de la jerarquía católica (y de las autoridades franquistas). Pilar Bellosillo, a principios de los sesenta, afirmaba que el hogar y el cuidado de los hijos no agotaban el rango de opciones abiertas a las mujeres adultas..$^{50}$ En su libro Nosotras, las solteras, María Salas sostuvo que el destino natural de las mujeres residía en el matrimonio y la maternidad. Ello no obstante, defendió que las adultas podían vivir una existencia plena sin desposarse ni tener hijos, puesto que cabía plasmar la inclinación maternal no sólo en la maternidad biológica sino en otras dimensiones de la existencia humana, entre ellas, una profesión, el voluntariado, el apostolado, las relaciones familiares distintas de las que ligan a las progenitoras con sus hijos o las relaciones de amistad. ${ }^{51}$ Repárese en que en aquella época las mujeres solteras de cierta edad eran consideradas seres fallidos, a quienes se aplicaban las descalificaciones corrientes entonces, entre ellas, las de "solteronas" o mujeres que "se habían quedado para vestir santos". ${ }^{52}$

\section{El sentimiento de pertenencia a la congregación de fieles}

Las feministas católicas se sintieron legitimadas para plantear las reivindicaciones arriba mencionadas (de acceso de las mujeres a la educación y la formación religiosa, de participación en el voluntariado y de respeto por opciones vitales distintas del matrimonio y la maternidad o los votos religiosos) sintiéndose miembros principales de la Iglesia, si bien marginados dentro de ella, y a la cual debían aportar. Según reflexionaba retrospectivamente María Salas, miembro del SESM y líder de Mujeres de Acción Católica, militó en esta organización "con sentido de pertenecer a una comunidad en la que puedes recibir, pero a la que tienes que dar según tus posibilidades. ${ }^{.53}$ En su libro titulado En tierra extraña, Lilí Álvarez demandó para los laicos un papel mucho más activo y autónomo en la Iglesia. ${ }^{54}$ Entendiendo a la Iglesia como pueblo de Dios, la autora insistió en la importancia de quienes no eran sacerdotes ni miembros de órdenes religiosas, al constituir ambos la base de la Iglesia: la comunidad de creyentes. Esta concepción de la Iglesia difería de la mantenida en el pasado, la cual ponía el énfasis en el papel director que la jerarquía ejercía sobre la feligresía. Esta obra alcanzó ocho ediciones. ${ }^{55}$ La amplia difusión de este y otros

50. MORENO, Mónica, "De la caridad...", p. 248.

51. SALAS, María, Nosotras, las solteras, Barcelona, Juan Flors, 1959.

52. Carmen VICTORY: Entrevista.

53. SALAS, María, Las siete palabras..., p. 22.

54. ÁLVAREZ, Lilí, En tierra extraña, Madrid, Taurus, 1956.

55. ÁLVAREZ, Lilí, Feminismo y espiritualidad, Madrid, Taurus, 1964, p. 2; CAMPO ALANGE, María, Mi atardecer, p. 123. 
escritos de Lilí Álvarez sobre el tema la convirtieron en uno de los principales exponentes de la teología del laicado en España.

En el libro titulado El seglarismo y su integridad Lilí Álvarez criticó explícitamente la marginación de las mujeres dentro de la Iglesia y reivindicó su participación en ella basándose en la teoría de la complementariedad de los sexos. Como ella misma afirmó: "El Génesis dice que 'Dios hizo el hombre varón y hembra'; por lo tanto, nada realmente humano puede darse sin ese encuentro y sin esta conversación entre uno y otro sexo; claro está, a condición de que conserven cada uno sus peculiaridades y complementarias características". ${ }^{56}$ Denunció, además, que las exigencias morales del Catolicismo para las fieles se redujeran muchas veces, en la práctica, a la represión de la sexualidad, a fin de cumplir con el sexto mandamiento ("no cometerás actos impuros"). Mientras, los requerimientos para los hombres eran mucho más amplios, e incluían todos los mandamientos, incidiendo relativamente poco en el sexto. Este doble estándar sexual y moral escondía una injusta infravaloración de la capacidad de las mujeres para el desarrollo moral. ${ }^{57}$

En años sucesivos Lilí Álvarez continuó defendiendo estas mismas opiniones de modo enfático. En $1962^{58}$ calificaba de "gran revelación de nuestra época" la aseveración de que "todos somos 'Iglesia' -no sólo los curas, las monjas y los obispos, como era la impresión común... por ambas partes-, todos tenemos que hacerla, que construirla" ${ }^{59}$ Fue en ocasiones muy duro el tono de sus críticas a los eclesiásticos que despreciaban a los laicos, por su "tendencia dirigista y mandona que mantiene a los demás en condición permanente de menores". ${ }^{60}$ Los laicos que reflexionaban teológicamente eran "atropellados sin comprensión ni caridad, y a veces hasta ni lealtad" por algunos ordenados ${ }^{61}$ otros eclesiásticos, sin atacar a estos seglares, miraban hacia otro lado cuando eran vilipendiados por ciertos clérigos, mostrando de este modo, "la pervivencia soterrada de la vieja mentalidad de casta [sacerdotal]", a la que Álvarez calificó de "vieja postura 'clasista", es decir, de "espíritu de coto cerrado de la clase 'que cuenta". Pidió la participación activa del laicado en la Iglesia concibiendo ésta como "Cuerpo Místico, en el cual todos los miembros están

56. ÁlVAREZ, Lilí, El seglarismo..., p.165. Numerosos escritos de feminismo católico defendieron la teoría de la complementariedad de los sexos, entre otros, ÁLVAREZ, Lilí et al.: Mujer y aceleración..., p. 49.

57. ÁLVAREZ, Lilí, El seglarismo..., pp. 168-169, 175-176.

58. ÁLVAREZ, Lilí, "Jerarquía y comunión o de la arriesgada condición de los seglares", Punta Europa, 7, 73, mayo (1962), pp. 49-59.

59. Ibid., p. 50.

60. Ibid., p. 58.

61. Ibid., p. 53. 
entrañablemente unidos y enlazados entre sí por la sangre de la Gracia que fluye de la Cabeza, y que hace que cualquier cosa que ocurra a una célla [sic], por pequeñita y humilde que sea, afecta y estremece a todas las demás células". ${ }^{62}$

En su reivindicación de la importancia del laicado como base de la Iglesia, las feministas católicas no estaban solas, sino luchando codo con codo con hombres seglares. Pero eran conscientes de que dentro de la Iglesia las seglares eran tratadas bastante peor que los seglares por la jerarquía. Y también percibían las feministas católicas que muchos hombres laicos (pero no todos) las menospreciaban y las consideraban inferiores. Según sintetizó en la entrevista Carmen Victory, presidenta de Mujeres de Acción Católica entre 1963 y 1968, incluso "dentro de la propia Acción Católica, el hombre era el hombre."

De nuevo, estas ideas correspondían a desarrollos que ocurrían en la Iglesia internacional. El Concilio Vaticano II (1962-1965) enfatizó la importancia de los seglares en la Iglesia. Se les permitió participar en algunas sesiones. Una de estas auditoras laicas fue Pilar Bellosillo, presidenta de Mujeres de Acción Católica entre 1952 y 1963, quien desarrollaría una impresionante carrera internacional, ocupando algunos de los más altos puestos de responsabilidad permitidos a una mujer en el mundo católico. Desde 1952 era vocal del Consejo de la Unión Mundial de Organizaciones Femeninas Católicas (UMOFC). Presidió la UMOFC entre 1961 y 1974, y la Confederación de Organizaciones Internacionales Católicas entre 1965 y $1971 .{ }^{64}$ Desde los años cincuenta se celebraron en Roma congresos internacionales de seglares: el primero en 1951, el segundo en 1958 y el tercero en 1967. En ellos se reclamó una mayor participación de los laicos en la renovación de la Iglesia y en la discusión teológica, su acceso a puestos de toma de decisiones de la Iglesia, así como que fueran tratados por la jerarquía eclesiástica no como menores de edad en materia religiosa sino como miembros vitales de la Iglesia. Se trató de eventos de grandes proporciones. Por ejemplo, al tercero asistieron aproximadamente 3.000 personas, la mayoría seglares, procedentes de 103 países. ${ }^{65}$ En algunos de ellos participaron feministas católicas españolas. Así, en el tercero estuvieron presentes la mencionada Pilar Bellosillo y Lilí Álvarez, miembro del SESM, invitada por el comité organizador del congreso en calidad de experta internacional. ${ }^{66}$

62. Ibid., p. 55.

63. Carmen VICTORY: Entrevista.

64. SALAS, María, y María T. RODRÍGUEZ, Pilar Bellosillo..., pp. 42, 127.

65. CUADERNOS PARA EL DIÁLOGO (ed.), El pueblo de Dios en marcha, Madrid, Cuadernos para el Diálogo, 1968, pp. 247-248.

66. Ibid., p. 191. RODRÍGUEZ, María Teresa, "Mujer y pensamiento religioso en el franquismo", Ayer, 17 (1995), pp. 173-200. 


\section{La consecución de los derechos individuales: una batalla secundaria}

Hasta ahora he mantenido que las feministas católicas dirigieron sus reivindicaciones sobre todo hacia las propias mujeres, y no tanto hacia el Estado, para que tomaran conciencia de su déficit educativo y cultural y su confinamiento en los hogares (con su correspondiente ausencia en otros ámbitos), adquirieran formación y participaran en la sociedad y la Iglesia de modo activo. Es preciso aclarar que, ocasionalmente, también criticaron la falta de derechos individuales de las mujeres e, implícita o explícitamente, pidieron a las autoridades políticas su reconocimiento. Por ejemplo, ya en los años cincuenta apareció en las publicaciones de Mujeres de Acción Católica algún artículo cuestionando ciertos aspectos de la inferioridad jurídica de las casadas (o de las viudas), si bien se trataba todavía de casos aislados. Así, en 1957 Senda publicó una entrevista a un profesor de derecho de la Universidad Central, quien criticaba que el Código Civil otorgara la patria potestad de los hijos legítimos solamente al padre. También denunciaba que la viuda perdiera la patria potestad sobre sus hijos si contraía un nuevo matrimonio; ${ }^{67}$ este precepto fue eliminado en la reforma del Código Civil de $1958 .^{68}$ En 1967, 1518 mujeres firmaron un documento titulado "Por los derechos de la mujer española", dirigido al vice-presidente del gobierno. Este escrito reivindicaba ciertos derechos laborales (la implantación real de la igualdad salarial, la prohibición de despido a las trabajadoras gestantes y la posibilidad de la lactancia en el lugar de trabajo), sanitarios (el seguimiento de los embarazos), reproductivos (la despenalización de la contracepción), civiles de las casadas (la patria potestad conjunta y la supresión de la autorización marital) y el reconocimiento de la separación matrimonial. Fue firmado por algunas feministas católicas, entre ellas, María Campo Alange. ${ }^{69} \mathrm{Al}$ año siguiente, ante la propuesta de la Sección Femenina de conceder un sueldo a las amas de casa con responsabilidades familiares, el Seminario publicó en $A B C$ una carta al director manifestándose en contra de la concesión de este derecho, por entender que premiaba la reclusión de las españolas en la domesticidad. ${ }^{70}$ Las feministas católicas también criticaron la autorización marital que necesitaban las mujeres casadas en muchos actos. ${ }^{71}$

67. SALAS, María, "Un fiscal que resulta ser defensor: José Ma Castán Vázquez defiende los derechos de la mujer", Senda, 164, marzo (1957), p. 10.

68. RUIZ, Rosario, ¿Eternas menores?..., p. 150.

69. El documento, con algunas de las firmas, puede consultarse en DI FEBO, Giuliana, Resistencia y movimiento..., pp. 219-224.

70. ÁLVAREZ, Lilí et al.: "El trabajo del ama de casa", ABC, 24 febrero (1968), p. 40.

71. ÁLVAREZ, Lilí et al.: Mujer y aceleración, p. 18; Ángela R. DE SILVA: Entrevista. 
No obstante lo anterior, las mencionadas demandas dirigidas al Estado acerca de los derechos individuales no constituyeron la batalla principal de las feministas católicas. Como sintetizó María Salas al referirse al SESM desde su fundación en 1960, "[d]esde el principio concebimos el feminismo no como una reivindicación de derechos sino también en las relaciones sociales y estructurales". ${ }^{72}$ Además, es necesario precisar que, en términos generales y con excepciones, no reivindicaron algunos derechos, sobre todo los ligados a la sexualidad y la reproducción, que años más tarde constituirían metas centrales de la segunda oleada de movimientos feministas en los países occidentales, tales como el acceso a la anticoncepción y al aborto y el derecho a disponer del propio cuerpo para cualquier práctica sexual libremente consentida, así como el divorcio. En general, no constituyeron objetivos de las feministas católicas, quienes se mantuvieron con frecuencia en silencio sobre estos temas. ${ }^{73}$

\section{Conclusión}

Si bien en la obra de T. H. Marshall la ciudadanía suele entenderse como un conjunto de derechos individuales (civiles, políticos y sociales) conferidos por el Estado a los miembros de una comunidad política, otra lectura de esta misma obra nos lleva a concebirla como el estatus de quienes participan como miembros plenos en una comunidad (sea ésta política o de otro tipo), animados por un sentimiento de pertenencia a la misma. Utilizando esta definición alternativa de ciudadanía, en este artículo he analizado los esfuerzos individuales y colectivos de ciertas mujeres encuadradas en organizaciones de la Iglesia o próximas a ella (las aquí llamadas "feministas católicas") por que las mujeres ampliaran su participación en la sociedad y en la propia Iglesia. Para ello, les animaron a que adquirieran educación general y formación religiosa en particular, les instaron a que no redujeran su existencia a ser madres y esposas, defendieron, en la práctica y en la teoría, otras opciones vitales distintas del matrimonio y la maternidad (por ejemplo, la soltería) y exhortaron a las de todo estado civil y condición social a interesarse por todo lo que aconteciera más allá de su hogar y a participar en el voluntariado. Defendieron sin descanso esta visión de la ciudadanía animadas por un sentimiento de la propia valía y de pertenencia a la Iglesia, entendida ésta como pueblo de Dios y como

72. SALAS, María, "Acto en memoria de María Campo Alange", en ASOCIACIÓN ESPANOLA DE MUJERES UNIVERSITARIAS (ed.), María Campo Alange: In memoriam, Madrid, Asociación Española de Mujeres Universitarias, 1986.

73. VALIENTE, Celia, "Age and feminist activism: The feminist protest within the Catholic Church in Franco's Spain", Social Movement Studies, vol. 14, nº 4 (2015), pp. 473-92. 
cuerpo místico de Cristo. En ocasiones reivindicaron ante las autoridades políticas el reconocimiento de ciertos derechos individuales, si bien esta batalla no fue la principal entre las que libraron. Por sus demandas padecieron el desprecio de muchos hombres (y mujeres) en la Iglesia y la sociedad, y hubieron de sortear continuamente oposición a sus planteamientos.

Reconocer la existencia y la importancia del feminismo católico durante el régimen de Franco no implica negar ni ocultar sus (significativos) límites, entre ellos su silencio ante ciertas cuestiones, sobre todo las relativas a la sexualidad, la reproducción y el divorcio, o el elitismo de algunas de sus actuaciones, por ejemplo, las dirigidas a mejorar la eficiencia de las tareas domésticas y de cuidados desempeñadas en las familias de estratos desfavorecidos. Significa entender que ciertas mujeres encontraron su propia voz y la autonomía necesarias para cuestionar el ideal de vida femenino propuesto por el régimen y la jerarquía eclesiástica, que lo hicieron antes de lo estimado habitualmente por la historiografía (desde los años cincuenta en vez de los sesenta o los setenta), en ámbitos diferentes de los identificados normalmente por los estudios de género (la propia Iglesia o las proximidades de ella en lugar de la oposición a la dictadura), y animadas por un sentimiento religioso que les impulsó (pero también impuso restricciones notables) a lo que reivindicaron (mientras que los estudios feministas sobre España han solido subestimar, cuando no directamente ignorar, la religión como factor impulsor de la demanda de la mejora del estatus de las mujeres). Futuros análisis habrán de continuar excavando en el pasado, a fin de desvelar los esfuerzos individuales y colectivos de algunas de ellas por contestar las cortapisas impuestas a sus existencias, por limitados que parezcan examinados con ojos actuales.

\section{Entrevistas}

Álvarez de Miranda, Consuelo. 2010. Hija de Consuelo de la Gándara, Seminario de Estudios Sociológicos sobre la Mujer. Madrid, 19 marzo.

Álvarez de Miranda, Pedro. 2010. Hijo de Consuelo de la Gándara, Seminario de Estudios Sociológicos sobre la Mujer. Madrid, 3 February.

Aradillas, Antonio. 2009. Consiliario Nacional de Mujeres de Acción Católica. Madrid, 31 agosto.

Borreguero, Concepción. 2009. Seminario de Estudios Sociológicos sobre la Mujer. Madrid, 1 octubre y 22 octubre.

de Silva, Ángela R. 2009. Mujeres de Acción Católica. Madrid, 9 noviembre.

del Amor, María. 2010. Nuera de María Campo Alange, Seminario de Estudios Sociológicos sobre la Mujer. Madrid, 13 abril.

Jiménez, María. 2009. Seminario de Estudios Sociológicos sobre la Mujer. Madrid, 25 agosto. 
Pérez-Seoane, Carmen. (2009). Seminario de Estudios Sociológicos sobre la Mujer. Madrid, 1 octubre.

Quereizaeta, María. 2009. Mujeres de Acción Católica. Madrid, 7 octubre.

Rodríguez-Ponga, José M. 2010. Nieto de María Campo Alange, Seminario de Estudios Sociológicos sobre la Mujer. Madrid, 16 marzo.

Salamanca, Soledad. 2010. Hija de María Campo Alange, Seminario de Estudios Sociológicos sobre la Mujer. Madrid, 6 abril.

Salas, Carmen. 2009. Mujeres de Acción Católica. Madrid, 25 septiembre.

Salas, Purificación. 2009. Seminario de Estudios Sociológicos sobre la Mujer. Madrid, 9 septiembre.

Victory, Carmen. 2009. Mujeres de Acción Católica de la Mujer. Madrid, 14 septiembre.

Vindel, Elena. 2010. Hija de Elena Catena, Seminario de Estudios Sociológicos sobre la Mujer. Madrid, 12 febrero.

\section{BIBLIOGRAFÍA}

Álvarez, Lilí, En tierra extraña, Madrid, Taurus, 1956.

Álvarez, Lilí, El seglarismo y su integridad, Madrid, Taurus, 1959.

ÁlvareZ, Lilí, "Jerarquía y comunión o de la arriesgada condición de los seglares", Punta Europa 7 (73), mayo 1962, pp. 49-59.

Álvarez, Lilí, "Feminismo y espiritualidad", Madrid, Taurus, 1964.

Álvarez, Lilí, "La valoración del ama de casa, clave para el destino femenino", Cuadernos para el Diálogo número extraordinario sobre la mujer, 1970, pp. 28-30.

Álvarez, Lilí, Borreguero, Concepción; Campo Alange, María et alii, "El trabajo del ama de casa”, ABC, 24-2-1968, p. 40.

Álvarez, Lilí; Borreguero, Concepción; Campo Alange, María et alii, "Mujer y aceleración histórica”, Madrid, Cuadernos para el Diálogo, 1970.

Bellosillo, Pilar, "Los movimientos de liberación de la mujer", Incunable, 9 (310), 1975, pp. 8-9.

Blasco, Inmaculada, "Las mujeres de Acción Católica durante el primer franquismo", en Tiempos de silencio: Actas del IV Encuentro de Investigadores del Franquismo, Valencia, 17-19 noviembre de 1999, Alzira, 7 i Mig, 1999, pp. 158-163.

Blasco, Inmaculada, Paradojas de la ortodoxia: política de masas y militancia católica femenina en España (1919-1939), Zaragoza, Prensas Universitarias de Zaragoza, 2003.

Campo Alange, María, La secreta guerra de los sexos, Madrid, Revista de Occidente, 1948.

Campo Alange, María, "Habla la mujer: Resultado de un sondeo sobre la juventud actual", Madrid, Cuadernos para el Diálogo, 1967.

Campo Alange, María, Mi atardecer entre dos mundos: Recuerdos y cavilaciones, Barcelona, Planeta, 1983.

CAPrarella, Marcello, "La ciudadanía secuestrada: La etapa franquista", en Pérez LedesMA, Manuel (ed.), De súbditos a ciudadanos: Una historia de la ciudadanía en España, Madrid, Centro de Estudios Políticos y Constitucionales, 2007, pp. 311-341. 
Cuadernos para el Diálogo, El pueblo de Dios en marcha, Madrid, Cuadernos para el Diálogo, 1968.

DE la Gándara, Consuelo, "Promoción cultural", Cuadernos para el Diálogo número extraordinario sobre la mujer, 12 (1970).

DI FEBO, Giuliana, Resistencia y movimiento de mujeres en España (1936-1976), Barcelona, Icaria, 1979.

Escario, Pilar; Alberdi, Inés; López-Accotto, Ana I., Lo personal es político: El movimiento feminista en la transición, Madrid, Instituto de la Mujer, 1996.

Ferree, Myra M.; Mueller, Carol M., "Feminism and the women's movement: A global perspective", en Snow, David A.; Soule, Sarah A.; Hanspeter, Mablen (eds.), The Blackwell Companion to Social Movements, 2004, pp. 576-607.

Katzenstein, Mary F., Faithful and fearless: Moving feminist protest inside the Church and military, Princeton, Princeton University Press, 1998.

Llona GonZÁlez, Miren, "El feminismo católico en los años veinte y sus antecedentes ideológicos”, Vasconia 25 (1998), pp. 283-299.

Marshall, Thomas H., Citizenship and social class and other essays, Cambridge, Cambridge University Press, 1950.

MARTín, María J., y María L. Bouvard, "Cursillo de racionalización del trabajo doméstico: Hablan las organizadoras y las alumnas”, Senda 250 (junio 1964), pp. 4-6.

Morcillo, Aurora G., True Catholic womanhood: Gender ideology in Franco's Spain. Dekalb, Northern Illinois University Press, 2000.

Morcillo Gómez, Aurora. En cuerpo y alma: Ser mujer en tiempos de Franco, Madrid, Siglo XXI, 2015.

Moreno, Mónica, "De la caridad al compromiso: Las mujeres de Acción Católica (1958-1968)", Historia Contemporánea 26 (2003), pp. 239-265.

Mujeres de Acción Católica, Para ti, mujer. Madrid, 1957.

NASH, Mary, "Experiencia y aprendizaje: La formación histórica de los feminismos en España", Historia Social 20 (1994), pp. 151-72.

Pío XII, "La mujer en el momento actual", Circular para Dirigentes, 133 (1956), pp. 14-16.

RAdCLIFF, Pamela, Making democratic citizens in Spain: Civil society and the popular origins of the transition, 1960-1978, Palgrave, Macmillan, 2011.

RAY, R.; KorTeWeg, A. C., Women's movements in the Third World: Identity, mobilization, and autonomy. Annual Review of Sociology, 25 (1999), pp. 47-71.

Rodríguez, María T., Mujer y pensamiento religioso en el franquismo. Ayer, 17 (1995), pp. 173-200.

Ruiz, Rosario, ¿Eternas menores? Las mujeres en el franquismo, Madrid, Biblioteca Nueva, 2007.

SALAS, María, "Un fiscal que resulta ser defensor: José Mª Castán Vázquez defiende los derechos de la mujer", Senda 164 (marzo 1957), p. 10.

SALAS, María, Nosotras, las solteras, Barcelona, Juan Flors, 1959. 
Salas, María, "Acto en memoria de María Campo Alange", en María Campo Alange: In memoriam, Madrid, Asociación Española de Mujeres Universitarias, 1986.

Salas, María, Las siete palabras de Mary Salas, Madrid, Promoción Popular Católica, 1996

Salas, María; Rodríguez; María T., Pilar Bellosillo, Nueva imagen de la mujer en la Iglesia, Madrid, Federación de Movimientos de la Acción Católica Española, 2004.

SCANLON, Geraldine M., La polémica feminista en la España contemporánea (18681974), Madrid, Siglo XXI, 1976.

SENDA, "Pío XII y la mujer", Senda 153 (1956), pp. 6-7.

SENDA, "La Acción Católica: Centros de formación familiar", Senda 229 (agosto 1962), p. 15.

Valiente, Celia, "Age and feminist activism: The feminist protest within the Catholic Church in Franco's Spain", Social Movement Studies 14 (4), 2015, pp. 473-492 DOI: $10.1080 / 14742837.2014 .947252$.

VALIEnte, Celia, "Social movements in abeyance in non-democracies: The women's movement in Franco's Spain", Research in Social Movements, Conflicts and Change, 38 (2015), pp. 259-90. 